\title{
ДЕСТАБИЛИЗИРУЮЩИЕ ФАКТОРЫ РАЗВИТИЯ ЭКОНОМИКИ: САНКЦИИ И ИХ ИНВЕСТИЦИОННЫЕ ПОСЛЕДСТВИЯ
}

\author{
(c) 2019 Зельднер Алексей Григорьевич \\ доктор экономических наук, профессор, главный научный сотрудник \\ Институт экономики Российской академии наук \\ 117218, г. Москва, Нахимовский пр-т, д. 32 \\ E-mail: tzeldner@gmail.com
}

Антироссийские санкции оказывают системное влияние на социально-экономические процессы, на темпы роста ВВП, на возможности обновления технологического оборудования и многое другое. В статье мы подробно рассматриваем влияние санкций на отток капитала из страны, на ограничение доступа к льготным кредитам и на некоторые внутренние возможности получения инвестиционных ресурсов.

Ключевые слова: санкции, инвестиции, финансы, кредиты, бюджет.

Санкции - следствие реакции мировой общественности на присоединение Крыма, дела Скрипалей и некоторых других событий, не имеющих оправдания со стороны правительств развитых стран, и по-другому воспринимаемых в России. Антироссийские санкции в определенной мере синоним торговой войны, но для их введения необходим понятный для народа повод. Первые санкции Россия получила после дела Магницкого, затем последовал Крым, далее, якобы отравление в Англии, и мы получили санкции от США, ЕС, Северной Америки (Канада), Австралии и ряда других развитых стран.

По мнению участников Всемирного экономического форума (Давос, 2019 г.), ожидается усиление конфронтации на международном уровне, как в геополитической, так и в геоэкономической сферах. Опрос экспертов показал, что в 2019 г. ожидается рост рисков, «связанных с «экономической конфронтацией между ведущими державами» (91\%), «размыванием международных торговых правил и соглашений» (88\%) и «политической конфронтацией между ведущими державами» (85\%)» [1]. Все эти риски приводят к снижению уровня доверия стран друг к другу и соответственно затрудняют совместные решения многих социально-экономических, экологических и технологических проблем. Главные опасности для мировой" и в значительной мере для российской экономики, активно участвующей в мировой торговле,- это пре- вращение торговли в элемент международного противостояния, политическая нестабильность в мире, потеря доверия развитых стран друг к другу и, как следствие, гонка вооружения.

Следует отметить, что не только санкции способствовали низкому тренду развития нашей экономики (хотя они оказали достаточно существенное негативное влияние). Стагнация российской экономики восходит к 90-м годам прошлого века в виде непродуманной приватизации, приведшей к структурным перекосам в промышленности, отсутствии конкуренции, постоянном давлении на малый бизнес, отсутствии координации между политиками и экономистами.

В современных условиях, характеризующихся низкими темпами роста экономики и постоянным ожиданием дальнейших санкций, страна переходит к уже проверенной модели развития - накоплению резервов, повышению ставок ЦБ и росту кредитных ставок и налогов. Может, это и выручает на коротком промежутке времени, но мы практически замораживаем модернизацию экономики, и это в условиях ухудшения международного геополитического положения.

На 10-м Гайдаровском форуме в Москве (январь 2019 г.), позиционирующем себя «самой авторитетной экономической конференцией в России» первый вице-премьер А. Силуанов назвал антироссийские санкции и международные торговые войны «главным риском, который мо-

\footnotetext{
* По данным аналитиков японского банка Nomura, мировую экономику в ближайшие годы ждет спад, хотя и не слишком сильный. Среди главных причин спада называются торговая война и ее последствия, а также жесткая денежно-кредитная политика Федеральной резервной системы.
} 
жет не позволить уже в 2024 г. реализовать России свои стратегические цели. По оценкам экспертов Bloomberg Economics, объем российской экономики сейчас на $6 \%$ меньше, чем мог бы быть, из-за западных санкций. А председатель Счетной палаты Алексей Кудрин заявлял в августе 2018 г., что влияние международных санкций на экономику России увеличилось до 0,5\% ВВП [2].

Санкции, оказывающие влияние на российских производителей, отражаются и на наших партнерах в других странах. По данным президента Итало-Российской торговой палаты В. Трани, в 2014 г. «ущерб для итальянских компаний, которые торговали с Россией напрямую, более чем 1 млрд. евро, не считая ущерба от упущенной прибыли» [3]. По данным премьер-министра Д. Медведева, общий объем потерь ЕС от санкций составляет около 100 млрд. евро [4].

Введенные антироссийские санкции, как следствие внешнеполитических событий, оказали системное влияние на экономику страны. Это проявилось в стремлении отечественных и иностранных инвесторов к оттоку капитала, в ухудшении возможностей кредитования, в поиске внутренних резервов за счет усиления влияния банков на воспроизводственный процесс. Рассмотрим часть этих позиций более подробно.

Отток капитала. Санкции оказали влияние на отток инвестиций. Повысилась неопределенность для бизнес-инвестиций и для населения, ускорился отток капитала. По данным Центробанка РФ (от 17.01.2019), чистый отток капитала из России в 2018 г. вырос с 25,2 млрд. долл. в 2017 г. до 67,5 млрд. долл. в 2018 г. или почти в 2,7 раза [5].

Под ударом оказались и прямые иностранные инвестиции, так как вводится запрет на получение длинных инвестиционных кредитов, используемых в том числе и для структуризации и модернизации. По данным Центрального банка, на начало октября 2018 г. в Россию пришло 520 млрд. долл. иностранных инвестиций, а из страны за рубеж ушло 448 млрд. долл. Разница небольшая, в Бразилии, например, она составляет 400 млрд. долл. (у нас 72 млрд. долл.), в Польше -200 млрд. долл., в Чехии - 130 млрд. долл.
Существенно снизились и портфельные инвестиции в ценные бумаги. Перед кризисом 2008 г. их положительное сальдо достигало 350 млрд. долл., по данным на 2018 г.- в 2 раза меньше. Прочие инвестиции (в основном долгосрочные ссуды) крупным российским компаниям и банкам. У нас отрицательное сальдо (из России ушло 357 млрд. долл, а пришло 272 млрд. долл.). В целом «за последние 10 лет инвестиционное сальдо в пользу России менялось следующим образом: 2008 г. - 629 млрд. долл., через 10 лет 147 млрд. долл. Заемные средства в России сократились почти в 4,3 раза. В Бразилии положительное сальдо инвестиций составляет 900 млрд. долл., в Польше -422 млрд. долл, в Чехии -200 млрд. долл.» [6]. При этом, если ВВП в Бразилии и России примерно сопоставимы, то в Чехии и Польше существенно меньше.

Следует отметить, что помимо санкций ускорению бегства капитала из России, способствует и существующая программа в Евросоюзе по получению гражданства в обмен на покупку недвижимости или других вложений в экономику. По оценке Global Witness и Transparency International, за 10 лет продажа паспортов и золотых виз принесла в Европу 25 млрд. евро. Как сообщал Der Spiegel, под прицел Еврокомиссии попали прежде всего Греция, Кипр и Мальта, где главными покупателями гражданства стали россияне и граждане бывших советских республик. По данным правительства Мальты, каждый второй участник программы «Гражданство за инвестиции» действующей с 2013 года, предположительно, оказался выходцем из РФ“.

Руководство ЕС запускает масштабную реформу по проверке претендентов, получивших покупные паспорта в обмен на инвестиции. По заявлению Еврокомиссариата по вопросам юстиции «преступники ставят под угрозу безопасность Европы, поскольку хотят отмыть здесь свои капиталы»; «ЕС не должен становиться убежищем для коррупции и грязных денег».

Кредиты в условиях санкций. Наиболее существенные санкции связаны с запретом на получение дешевых (по меркам России) кредитов, что в итоге отразилось при вынужденном переходе на российские кредиты на росте

\footnotetext{
* https://www.finanz.ru/novosti/aktsii/rossiyskim-elitam-otrezhut-puti-begstva-v-evropu-1027888794 Среди тех, кто заплатил взнос в 650 тысяч евро, инвестировал не менее 350 тысяч евро в недвижимость и не менее 150 тысяч - в утвержденные правительством облигации за последние 3 года, оказались более 700 человек с типичными российскими именами и фамилиями - полные тезки крупных бизнесменов и чиновников, в том числе фигурирующих в списке Forbes.
} 
затрат во всех сферах, на колебании рубля и в итоге на реальных доходах населения. Дату массовых санкций можно отнести к 2014 г. В 2014 г. средняя ставка по кредитам в России составляла 11,1\%, в 2015 г. (после санкций), чтобы «помочь» производству, средняя ставка увеличилась до 15,7\% [7]. В США за этот же период кредитные ставки составили 2,5\% и 1,8\%, в Канаде - 3\% и 2,7\%, в Республике Корея - 4,2 и 3,5. В странах EC, соответственно: в Германии 4,9\% и 5,0\%, Финляндии - 3,9 и 4,2\%, Италии - 5,8\% и 5,2\%, Франции - 6\% и 6\% [7].

Конечно, для нас зарубежные кредиты были несомненно дороже, чем приведенные данные, но они не превышали существенно сложившиеся ставки. И как только были в 2014 г. запущены санкции, тут же наши банки увеличили кредитные ставки с 11, 1 до 15,7\%. Так что запрет на кредитование существенно отразился на внутреннем рынке страны.

Сокращение поступления в Россию заемных средств в связи с санкциями существенно ограничивает воспроизводственные возможности, связанные с развитием инфраструктуры и модернизацией наших организаций. В этих условиях очень важна мобилизация внутренних финансовых возможностей за счет профицита бюджета, положительного сальдо торгового баланса за счет целевой эмиссии под конкретные проекты. Но в структуре инвестиций в основном капитал кредиты банка последние годы не превышают 11\%. в 2015 г.- 8,1\%, 2016 г.- 10,4\%, 2017 г. - 10,9\% [8], из них 50\% - это кредиты иностранных банков, лояльно относящихся к нам стран.

В то же время мировая практика свидетельствует о том, что растет объем заемных средств, используемых для поддержания темпов и современного развития экономии. По данным Конференции ООН по торговле и развитию (UNCTAD), сейчас глобальная суммарная задолженность в мире составляет 250 трлн. долл. [9], что на 50\% превышает объем задолженности на момент кризиса 2008 г. и в три раза больше объема всей мировой экономики. То есть, по сути, в мировой экономике на единицу собственных средств приходится три единицы заемных. Но такая схема развития мировой экономики требует качественного управления [10], предсказуемого и ответственного, чего и не хватает нашей стране. Следует отметить, что санкции отрезали страну от льготных зарубежных кредитов, но, как раньше, так и в условиях стагнации, мы считаем низкий госдолг нашим преимуществом. Предпочтение отдается накапливанию резервов в ожидании кризиса, и высоким ставкам по кредитам, что ограничивает использование средств для модернизации экономики.

Система накопления резервов в фонде национального благосостояния приводит к тому, что недофинансируется технологическая модернизация и инновационное развитие. Вслед за государством на путь снижения инновационной активности стали и крупные олигархические структуры. Известно, что энергетическая отрасль России формирует почти четверть ВВП, но удельный вес инновационной активности организаций в сфере добычи топливно-энергетических ископаемых снижается. «В 2003 г. он составлял 7,2\%, в 2014 г. - 7,4\%, в 2015 г.-6,3\%, в 2016 г.- 5,6\%» [11].

Бюджетное правило в условиях санкций. Создание финансовой подушки безопасности в условиях замедления мирового экономического роста, пролонгирования ожидания наращивания санкций, роста налогов и кредитных ставок и невозможности преодоления отрицательного тренда снижения реальных доходов - с позиции правительства вполне оправдано. Но в ожидании дальнейших санкций возможно смягчение бюджетного правила, с тем чтобы не задействовать факторы, способствующие падению доходов населения, обостряющие протестные настроения.

Ослабление бюджетного правила уже наблюдалось в прошедшем 2018 г., цена отсечения составляла 41,2 долл. за баррель, в 2019 г. планируется установить цену отсечения, по данным Счетной палаты, в 43,2 долл., и в дальнейшем плавно повысить до 43,3 долл. за баррель. Но следует отметить, доходы сверх базовой цены в основном используются для покупки валюты и наращивания суммы Фонда национального благосостояния (ФНБ). Почти весь профицит бюджета в 2018 г. (2,7 трлн. руб.) был направлен на приобретение валюты. Пополнение ФНБ становится приоритетом для правительства. На 1 января 2019 г. в ФНБ находилось немногим больше 4 трлн. руб., или 3,8\% ВВП РФ. По данным Счетной палаты, в 2019 г. в ФНБ направят свыше 4 трлн. руб. дополнительных доходов. Объем ФНБ на конец 2021 г. должен составить, судя по заключению Счетной палаты, 14,3 трлн. руб., или 12,1\% ВВП. Тем самым покупка иностранной 
валюты становится одной из крупнейших статей расходов бюджетных средств, если быть точнее,- второй после социальной политики [12].

По данным директора аналитического департамента «Локо-Инвест» К. Тремасова «Сверхжесткая бюджетная консолидация, осуществленная в 2017-2018 гг. стала ключевым фактором низких темпов роста экономики, падения реальных доходов населения и резко возросшей дифференциации (неравенства) доходов». В этой связи необходимо отметить, что «расходы бюджета в 2018 г. составили беспрецедентно низкие 16,4\% ВВП, практически не изменившись по сравнению с предыдущим годом в номинальном выражении. В 2014-2016 гг. этот показатель находился на уровне 19-20\% ВВП, а ниже 18\% ВВП вообще не опускался» [12]. Трехлетний бюджет (2019-2021 гг.) также планируется с профицитом, но при этом его расходы заложены на уровне $17 \%$ ВВП в год.

Сложно однозначно оценить действия правительства: если бы была стабильная международная обстановка, устойчивые темпы роста мировой экономики и отсутствие санкций, изъятие бюджетных средств для покупки валюты и сокращения инвестиционного обеспечения модернизации экономики и развития инфраструктуры показалось бы нелогичным. Но в современных условиях, когда против России уже введены санкции и ожидается их усиление, формирование валютных резервов приобретает другой смысл. По сути, формируется резерв безопасности с учетом опыта, полученного в кризис 2008-2009 гг. И за счет чего в сложившихся условиях совершить рывок, на который настаивает правительство, ведь курс, взятый на наращивание резервов, предполагает и замедление темпов роста экономики.

Банки в условиях санкций. Низкий уровень участия банков на протяжении многих лет в активизации деятельности по стимулированию инвестиций в основной капитал связан в основном с тем, что вместо активного участия в воспроизводственной политике, они сосредотачивают свою деятельность на росте прибыли в основном за счет населения. При этом пользуются сложившимся последние годы падением реальных доходов населения, которое вынуждено занимать деньги в банке, по сути, для выживания. Известно, что в конце года ЦБ повышал кредитные ставки дважды, вслед за этим поднялись ставки по кредитам. В итоге по завершению 2018 г. население России «было должно банкам 14,9 триллиона рублей. Общий размер долга превысил 27\% от денежных доходов населения, установив абсолютный исторический рекорд. По итогам года портфель займов физлицам вырос на $22,8 \%$ - в 4 раза быстрее, чем банки наращивали кредитование корпоративного сектора (+5,8\% за год). На этом фоне банковская система в 2018 г., по данным ЦБ, заработала 1,345 трлн. рублей чистой прибыли, что в 1,7 раза больше показателя за 2017 год»". И главным источником роста прибыли становится население. По данным ВЦИОМа, 57\% населения имеет непогашенную задолженность, а у каждого второго долг перед двумя и больше банками или МФО.

Складывается впечатление, что российское правительство неадекватно оценивает сложившуюся ситуацию с последствием санкций, завершением этапа получения льготных зарубежных кредитов и возможностями приобретения новейших зарубежных технологий. Следует менять подход к управлению процессом импортозамещения. Прежде всего, необходимо активизировать роль банковской системы и, в частности Центрального Банка. В современных санкционных условиях он должен расширить свои функции, не только заниматься таргетированием инфляции, но и принять на себя ряд функций института развития.

Следовало бы использовать активы банковской системы в виде инвестиционных кредитов. «Их можно увеличить в 3-5 раз и вместо 1,5 трлн. руб. получить 4-7 трлн. руб.»**. Необходима также докапитализация институтов развития не только за счет бюджета, но и кредитов Банка России с тем, чтобы предоставлять кредитные ресурсы в пределах сложившегося в 2018 г. процента инфляции.

\footnotetext{
* ЦБ отчитался о рекордной прибыли банков. 25.01.2019. https://www.finanz.ru/novosti/aktsii/cb-otchitalsya-o-rekordnoy-pribyli-bankov-1027895918

** Аганбегян А.Г. Необходим финансовый форсаж. (Российская газета 12.11.2018). Опыт развития стран (США и др.) показывает и схему получения таких «длинных» денег: «путем наращивания дефицита бюджета и выпуска под эту сумму долговременных ценных бумаг, которые покупает Центробанк (имеющий 5 трлн. руб. денежных средств) и другие банки и фонды. Под залог этих ценных бумаг выдаются кредиты под 3-4\% годовых на срок под соответствующие технологические проекты»
} 


\section{Краткое заключение.}

Противодействию санкционному давлению, помимо смягчения международных отношений, может способствовать существенный рост производительности труда, который упирается в низкие темпы структуризации, модернизации и цифровизации российской экономики, а главное, в низкий уровень нормы инвестиций. Недостаток инвестиций может быть нивелирован за счет реализации до 2024 г. национальных проектов, но это при благоприятном стечении всех обстоятельств.

Где выход из санкционной ловушки? Если не считать необходимых усилий по выходу из международной изоляции, то главный путь - в мобилизации внутренних ресурсов, в импортозамещении, в структуризации и модернизации экономики не инновационной основе.

В сложившихся условиях следовало бы перейти к более полному изъятию рентных доходов, как минимум, за счет серьезного сокращения избыточных привилегий сырьевому сектору. В соответствии с данными Конфедерации труда России (КТР), налоговые льготы в 2018 г. существенно выросли, причем основным получателем этих льгот выступает нефтегазовый сектор. В основном налог на добычу полезных ископаемых и льготы по экспортной пошлине. НДПИ в 2018 г. составил 720 млрд. руб., половина этой суммы - льготы, предоставленные на «добор» нефти и газа из месторождений со значительной степенью выработки. Но, как считает эксперт, «степень выработанности определяется компанием-добытчиком самостоятельно, эффективных мер проверки не существует». «Льготы по экспортной пошлине в 2018 г. принесли около 170 млрд. руб. нефтяникам и и 90 млрд. руб.- газовикам. От экспортной пошлины правительство планирует отказаться в пользу повышенного НДПИ» [13], недостатки которого отмечены выше.

В ближайшие годы в развитии экономики многое будет связано с реализацией нацио- нальных проектов. Не стабильного развития, а прорыва ожидает Президент от правительства. Национальные цели, которые должны быть реализованы до 2024 г., поставленные в майском указе, трансформировались в 12 национальных проектов.

Ускорению роста бюджетных инвестиций, по замыслу правительства, поможет пенсионная реформа: численность пенсионеров, имеющих право на выплаты по старости, за 6 лет сократится на 2,7 млн. человек. В результате, по оценке Райффайзенбанка, бюджет сэкономит 1,5 триллиона рублей на инвестиции в национальные проекты и инфраструктурные стройки [14]. Повышение ставки НДС до 20\% может обеспечить около 0,6\% ВВП в год, что будет использовано на финансирование национальных проектов. Создание в 2019 г. Фонда развития, который будет привлекать деньги преимущественно на внутреннем рынке и финансировать инфраструктурные проекты, позволит увеличить расходы в среднем на 0,5\% ВВП. В целом расходы федерального бюджета вырастут на 1,1\% ВВП [15].

Замедление темпов роста мировой экономики в сочетании с санкциями и возникающим напряжением между развитыми странами (США и Китай) приведет к снижению роста экспорта товаров и услуг (кроме нефти и газа). Но при этом следует учитывать, что цены на нефть в долларах формирует не Россия, и мы не монополисты в сфере ее добычи*. У России вследствие слабого развития несырьевой экономики ограничена номенклатура товаров для внешнего рынка. Главные товары - после нефти и газа - зерно и оружие. Необходимо развивать конкурентоспособные производства, торговать не сырьем, а товарами глубокой переработки. Необходимо усилить стимулирование экспорта по типу таких развивающихся стран как Бразилия, Индия и др. Необходима структурная перестройка и модернизация экономики, а также более профессиональный и качественный подход к управлению социально-экономическим развитием страны.

\section{Библиографический список}

1. https://www.vedomosti.ru/economics/articles/2019/01/16/791584-davosskii-forum-riskah

2. Комраков А. Санкции возвращают страну в СССР. Независимая газета. http://www.ng.ru/economics/2018-11-25/1_7447_return.html

3. Зубов М. Пять лет под санкциями. Российская газета неделя. 27.09.2018. С. 16.

4. http://www.ng.ru/economics/2018-11-25/1_7447_return.html

\footnotetext{
* При этом следует отметить очень сильную зависимость страны от экспорта нефти и газа. Доля нефтегазовых поступлений в общем экспорте страны более половины, а в доходах бюджета - более трети.
} 
5. http://www.ng.ru/economics/2018-11-25/1_7447_return.html

6. Миркин Я. Они ушли и не обещали вернуться. Российская газета. 21.01.2019. По мнению Я. Миркина, «финансовые санкции - один из ключевых вызовов для экономики».

7. Российский статистический ежегодник 2017. Росстат. М. 2017. С. 665.

8. Инвестиции в основной капитал в РФ в 2017. С. 7. http://www.gks.ru/wps/wcm/connect/rosstat_main/rosstat/ $\mathrm{ru} /$ statistics/enterprise/investment/nonfinancial/

9. http://www.ng.ru/economics/2018-11-18/1_4_7441_economy.html http://www.ng.ru/authors/9274

10. Зельднер А.Г. Государство: выбор модели развития и системы управления. Проблемы теории и практики управления. 2018. № 5. С. 8-15.

11. Наука, технологии и инновации в России 2017. М. ИМПРАН. 2017. С. 76.

12. Независимая газета. 14.01.2019. http://www.ng.ru/economics/2019-01-14/14_7481_econ1.html

13. Смирнов Л. Богатые льготники против бедных пенсионеров. https://www.rosbalt.ru/ moscow/2019/01/24/1760027.html

14. В правительстве предложили россиянам еще три года потерпеть. 06.09.2018. https://www.finanz.ru/novosti/ aktsii/v-pravitelstve-predlozhili-rossiyanam-eshche-tri-goda-poterpet-1027513172

15. https://www.rbc.ru/economics/24/11/2018/5bf7e7449a7947baac456f6f?from=materials_on_subject

16. Зельднер А.Г. Экономический рост: состояние и проблемы // Экономические науки. 2018. № 1. С. 17-22.

17. Осипов В.С. Роль импортозамещения в формировании новой модели развития // Интеллект. Инновации. Инвестиции. 2017. № 5. С. 24-31

18. Аганбегян А.Г. Необходим финансовый форсаж. Российская газета 12.11.2018.

Поступила в редакцию 11.01.2019 